\title{
Mepilex Border Dressings for the Prevention of Pressure Ulcers Caused by Nephrostomy Tube Securement
}

\author{
Yang Qi, Guo Xiaoxia* \\ Department of Urology, The First Affiliated Hospital of Jinan University, Guangzhou, China \\ Email address: \\ guoxiaoxia2019@sina.com (Guo Xiaoxia) \\ ${ }^{*}$ Corresponding author \\ To cite this article: \\ Yang Qi, Guo Xiaoxia. Mepilex Border Dressings for the Prevention of Pressure Ulcers Caused by Nephrostomy Tube Securement. Science \\ Journal of Clinical Medicine. Vol. 9, No. 1, 2020, pp. 7-10. doi: 10.11648/j.sjcm.20200901.12
}

Received: December 16, 2019; Accepted: January 3, 2020; Published: January 23, 2020

\begin{abstract}
Objective: To investigate the clinical effectiveness of Mepilex Border dressings for the prevention of medical device-related pressure ulcers (MDR PUs) caused by the nephrostomy tube securement with the drainage tube. Methods: Equally randomized 60 obstructive hydronephrosis patients in our hospital who were treated by ultrasound-guided percutaneous nephrolithotomy (from March 2018 to March 2019) into observation group and control group. The observation group was applied dressings beneath the junctions of nephrostomy tubes and drainage tubes before secured with $5 * 5 \mathrm{~cm}$ I-shaped $3 \mathrm{M}$ elastic adhesive tape to avoid direct contact to patients' skin; the control group was only secured with $5 * 5 \mathrm{~cm}$ I-shaped $3 \mathrm{M}$ elastic adhesive tape to the bare skin. The incidences of skin indentations, local pain and pressure ulcers under the junctions were compared between two groups. Results: There were statistical significance $(\mathrm{P}<0.05)$ among two groups: all patients in control group $(\mathrm{n}=30)$ were presented with skin indentations in different degrees, 21 with local pain, 6 with first-stage pressure ulcers, while no evidence of the above situations was found in the observation group. Conclusions: Application of Mepilex Border dressings can prevent the occurrence of MDR PUs to improve patient comfort.
\end{abstract}

Keywords: Mepilex Border Dressings, Nephrostomy Tubes, Securement, Medical Device-Related Pressure Ulcers

\section{Introduction}

Urolithiasis-caused obstructive hydronephrosis as a common disease. It is a therapeutic principle to relieve obstruction, drain urine and protect renal function. At present, It can be simply treated by an effective operation called ultrasound-guided percutaneous nephrolithotomy [1-3] which requires insertion of nephrostomy catheter for urine drainage. Percutaneous renal puncture fistula guided by B-ultrasound is a simple and effective method for the treatment of obstructive hydronephrosis. It is particularly important to keep and fix the renostomy tube for drainage after puncture.

Catheter nursing, focusing on patency, is crucial in postoperative care, especially for pyonephrosis and hydronephrosis patients, but for nephrostomy tube-catheterized patients, detachment prevention becomes the key, which is usually performed by $3 \mathrm{M}$ elastic adhesive tape clinically. However, close contact to the prominent tube junctions may trigger malaise like local pain and skin indentations, and even medical device-related pressure ulcers
(MDR PUs) [4, 5] which can significantly increase pain, interfere with treatment and reduce patients' quality of life, or even result in medical disputes. Mepilex Border dressings were introduce to our department (from March 2018 to March 2019) for nursing and were well-received by both patients and their family for its simplicity and favorable outcomes. The study is reported as follows.

\section{Data and Methods}

\subsection{General Data}

Clinical data were collected from urolithiasis-caused obstructive hydronephrosis patients in the First Affiliated Hospital of Jinan University who were treated by ultrasound-guided percutaneous nephrolithotomy with postoperative nephrostomy tubes placement from March 2018 to March 2019. Patients were equally randomized into observation group and control group, each for 30.16 males and 14 females aged 23-74 (mean age 55.07 \pm 9.66 ) were 
enrolled in observation group with hydronephrosis (18 sever, 10 moderate, 2 mild); pyonephrosis (2 left, 4 right), urolithiasis (17 upper, 10 mid, 3 distal); catheterization time 3-15 days (average 7.59 \pm 3.15 days). 19 males and 11 females aged 20-75 (mean age 55.24 \pm 10.04 ) were enrolled in control group with hydronephrosis (15 sever, 14 moderate, 1 mild); pyonephrosis (3 left, 5 right), urolithiasis (18 upper, 9 mid, 3 distal); catheterization time 4-14 days (average 7.72 \pm 2.53 days). Two groups were comparable in terms of gender, age, degrees of hydronephrosis and catheterization time with no statistical significance $(P>0.05)$.

\subsection{Material and Methods}

\subsubsection{Materials}

Mepliex Border dressings (Molnlycke Health Care AB, Gothenburg, Sweden, Figure 1); disposable drainage tubes specialized for nephrolithotomy postoperative care (Bioteque Corporation, Taiwan, China); 3M medical elastic adhesive tape (3M Japan Limited Health Care Company).



Figure 1. Mepliex Border Dressings produced by Mölnlycke.

\subsubsection{Fixation}

The junctions of postoperative tubes in the observation group were first centred on the $10 \times 10 \mathrm{~cm}$ Mepliex Border dressings before secured with $5 \times 5 \mathrm{~cm}$ I-shaped $3 \mathrm{M}$ elastic adhesive tape to ensure drainage patency and avoid detachment (dressings replaced every 7 days); the control group were secured only with same tape that was slightly repositioned once a day during which the skin inspection was conducted (Figure 2).

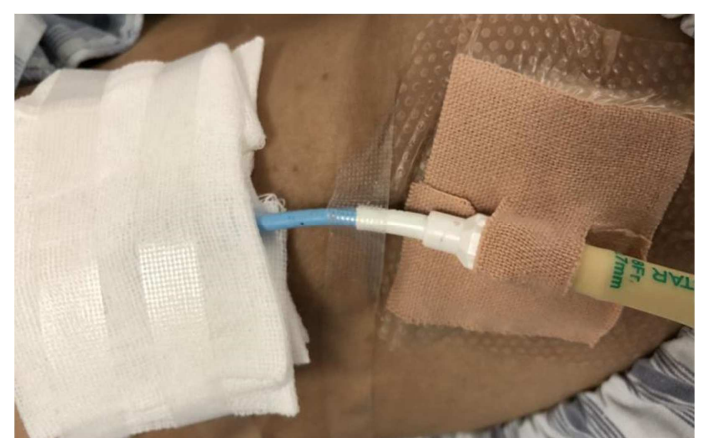

Figure 2. Application of Mepliex Border Dressings in Nephrostomy Tube Securement.

\subsubsection{Evaluation}

Incidences of skin indentations on applied areas; local pain assessment by Numerical Rating Scale (NRS) and Wong-baker FACES Pain Rating Scale; incidences of MDR PUs determined by the classification system [6] in 2014 Prevention and Treatment of Pressure Ulcers: Clinical Practice Guideline.

\subsection{Statistical Methods}

Data was analyzed by SPSS17.0 for chi-square test and $\mathrm{P}<0.05$ was considered statistically significant.

\section{Results}

\subsection{Incidences of Skin Indentations Beneath the Junctions of Nephrostomy Tubes and Drainage Tubes}

Skin indentations (depth varied from 0.1-0.2 cm) occurred in all patients in control group while no evidence of that was found in observation group, indicating statistical significance $(\mathrm{P}=0.000)$ as shown in Table 1 .

Table 1. Incidences of Skin Indentations.

\begin{tabular}{lll}
\hline Group & Positive & Negative \\
\hline Observation & 0 & 30 \\
Control & 30 & 0 \\
$P$ & & 0.000 \\
\hline
\end{tabular}

\subsection{Local Pain Assessed by NRS on the Applied Areas of} Nephrostomy Tubes connecting with Drainage Tubes

Local pain occurred in 21 patients in control group (10 scored 1, 8 scored 2, 3 scored 3, NRS) while no evidence of that was found in observation group with a significant difference $\left(\chi^{2}=32.308, \mathrm{P}=0.000\right)$ as shown in Table 2 .

Table 2. Incidences of Local Pain.

\begin{tabular}{lll}
\hline Group & Positive & Negative \\
\hline Observation & 0 & 30 \\
Control & 21 & 9 \\
$P$ & & 0.000 \\
\hline
\end{tabular}

\subsection{Comparisons of the Incidences of MDR PUs Between Two Groups}

6 patients in control group suffered from Stage I MDR PUs while no evidence of that was found in the observation group, with a significant difference $\left(\chi^{2}=6.671, \mathrm{P}=0.01\right)$ as shown in Table 3.

Table 3. Incidences of MDR Pus.

\begin{tabular}{lll}
\hline Group & Positive & Negative \\
\hline Observation & 0 & 30 \\
Control & 6 & 24 \\
$P$ & & 0.01 \\
\hline
\end{tabular}




\section{Discussion}

To minimize infection and protect renal function, postoperative nephrostomy tube securement for drainage is usually conducted after ultrasound-guided percutaneous nephrolithotomy on urolithiasis-caused obstructive hydronephrosis patients. Patients enrolled in this study were all applied nephrostomy tubes connecting with hard drainage tubes which were simply secured by medical tape with no dressings in control group. Vertical pressure to patients' skin elevated by long-term securement and the friction increased by spontaneous movements could both contribute to local skin injuries. According to NRS, 21 patients in control group suffered from mild pain (10 scored 1,8 scored 2, 3 scored 3) while no evidence of that were found in observation group. Therefore, we assume that the pain was associated with the hardness of catheter connectors and friction, which is in line with relevant literature and reports [7-9].

In this study, different degrees of skin indentations were found in control group, including 6 patients with Stage I pressure ulcers: intact skin with non-blanchable erythema, connector-shaped indentations and clear edges to the surrounding tissue, which all recovered (good blood circulation and smooth skin in the localized areas) through applying sanyrene and gauze and constantly repositioning the tape. In this case, more nursing time was required and patients were subjected to pain and anxiety that had substantial impacts on quality of life. It has been reported that solid medical devices create more friction and are more likely to trigger pressure ulcers, even MDR PUs (injuries develop when underlying tissue are subjected to a sustained pressure or shear from medical devices) [10-12], and foam dressings are now recommended by pressure ulcers prevention guideline to relieve pressure so as to protect the skin $[6,13-14]$.

In observation group, Mepliex Border dressings made remarkable outcomes as no evidence of MDR PUs was found among all patients. It substantially reduced nursing burden as no constant replacement was required (changed every 7 days). Also, Mepliex as barriers can effectively ease the vertical pressure brought by the junctions and friction caused by body movement. It is a kind of foam dressings with soft retention layer that can keep good blood circulation and relieve pressure by providing greater load redistribution, and has been proven to be an effective clinical preventive measure for pressure ulcers [15-17].

\section{Conclusions}

In conclusion, Mepliex Border dressings can work effectively in the prevention of MDR PUs caused by nephrostomy tube securement (mainly for load redistribution and friction reduction) while ensure drainage patency. In the second fixed special drainage tube, such as fixing the end of renal fistula and the connection of drainage tube, we add Mepikang application between skin and fistula to avoid joint friction to skin. The application of Meipikang application can effectively prevent the occurrence of catheterized pressure sore, reduce the pain of patients, improve comfort. Additional application of Mepliex Border dressings is particularly efficacious in alleviating friction between patients' skin and special-shaped connectors so as to minimize the incidences of MDR PUs. It is worthy to recommend for clinical application as it lessens patients' pain, reduces nursing burden and optimizes postoperative treatment for better patient satisfaction and clinical outcomes.

\section{References}

[1] Cheong, N. F., Loon, Y. W., Benjamin, L. T. Y., Kiat, T. J., Kit, N. K., \& Kiat, L. S.. (2017). Ultrasound-guided percutaneous nephrolithotomy: advantages and limitations. Investigative and Clinical Urology, 58 (5), 346-352.

[2] 2. Song, Y., Ma, Y. N., Song, Y. S., \& Fei, X.. (2015). Evaluating the learning curve for percutaneous nephrolithotomy under total ultrasound guidance. PLOS ONE, $10(8), \mathrm{e} 0132986$.

[3] Karami, Hossein, Rezaei, Alireza, Mohammadhosseini, Mojtaba, Javanmard, Babak, Mazloomfard, Mohsen, \& Lotfi, Behzad.. Ultrasonography-guided percutaneous nephrolithotomy in the flank position versus fluoroscopy-guided percutaneous nephrolithotomy in the prone position: a comparative study. Journal of Endourology, 24 (8), $1357-1361$

[4] Lavallée, Jacqueline F., Gray, T. A., Dumville, J., \& Cullum, N. (2019). Preventing pressure ulcers in nursing homes using a care bundle: a feasibility study. Health \& Social Care in the Community, 27 (4), e417-e427.

[5] Stéphanie F. Bernatchez, Mengistu, G. E., Ekholm, B. P., Sanghi, S., \& Theiss, S. D.. (2015). Reducing friction on skin at risk: the use of $3 \mathrm{~m}$ TM cavilon $\mathrm{TM}$ no sting barrier film. Advances in Wound Care, 4 (12), 705-710.

[6] Pittman, J., Beeson, T., Kitterman, J., Lancaster, S., \& Shelly, A.. (2015). Medical device-related hospital-acquired pressure ulcers: development of an evidence-based position statement. Journal of Wound Ostomy \& Continence Nursing, 42 (2) 151-154.

[7] Jacqueline F Lavallée, Gray, T. A., Dumville, J. C., \& Cullum, N.. (2019). Preventing pressure injury in nursing homes: developing a care bundle using the behaviour change wheel. BMJ Open, 9 (6), e026639.

[8] Black, J., Alves, P., Brindle, C. T., Dealey, C., Santamaria, N., \& Call, E., et al. (2015). Use of wound dressings to enhance prevention of pressure ulcers caused by medical devices. International Wound Journal, 12 (3), 322-327.

[9] Holroyd, S., \& Graham, K.. (2014). Prevention and management of incontinence-associated dermatitis using a barrier cream. British Journal of Community Nursing, 19 (Sup12), 32-8.

[10] Black, J., Clark, M., Dealey, C., Brindle, C. T., Alves, P., \& Santamaria, N., et al. (2015). Dressings as an adjunct to pressure ulcer prevention: consensus panel recommendations. International Wound Journal, 12 (4), 484-488. 
[11] Fossum, M., Ehnfors, M., Svensson, E., Hansen, L. M., \& Ehrenberg, A.. (2013). Effects of a computerized decision support system on care planning for pressure ulcers and malnutrition in nursing homes: an intervention study. International Journal of Medical Informatics, 82 (10), 911-921.

[12] Call, E., Pedersen, J., Bill, B., Black, J., Alves, P., \& Brindle, C. T., et al. (2015). Enhancing pressure ulcer prevention using wound dressings: what are the modes of action?. International Wound Journal, 12 (4), 408-413.

[13] Thorpe, \& Elaine. (2016). Prophylactic use of dressings for pressure ulcer prevention in the critical care unit. British Journal of Nursing, 25 (12), S6-S12.

[14] Byrne, J., Nichols, P., Sroczynski, M., Stelmaski, L., \& Carlin, K.. (2016). Prophylactic sacral dressing for pressure ulcer prevention in high-risk patients. American Journal of Critical Care, 25 (3), 228-234.
[15] Woo, K. Y., Coutts, P. M., Price, P., Harding, K., \& Sibbald, R. G.. (2009). A randomized crossover investigation of pain at dressing change comparing 2 foam dressings. Advances in Skin $\&$ Wound Care, 22 (7), 304-310.

[16] Waring, M., Bielfeldt, S., M?Tzold, K., Wilhelm, K. P., \& Butcher, M.. (2011). An evaluation of the skin stripping of wound dressing adhesives. Journal of Wound Care, 20 (9), $412-422$.

[17] Marshall, C., Shore, J., Arber, M., Cikalo, M., Oladapo, T., \& Peel, A., et al. (2019). Mepilex border sacrum and heel dressings for the prevention of pressure ulcers: a nice medical technology guidance. Applied Health Economics and Health Policy, 17 (4): 453-465. 